\title{
On High Vacuum Densification of Soft Foundation Treatment
}

\author{
Mei Ling GUO',a \\ ${ }^{1}$ Continuing Education College, Guangdong University of Science and Technology, 523083, Dongguan, China
}

\begin{abstract}
The high vacuum densification, which inserted the vacuum tube to increase the drainage channel, set up the improved drainage system so that it can effectively reduce the underground water level, can be used for the reinforcement of the deep soft foundation. According to analyze the preparation and process of high vacuum densification, and summarize the control points of high vacuum densification, it renders great value to the constuction of soft foundation treatment.
\end{abstract}

\section{Introduction}

The high vacuum densification is a kind of soft foundation reinforcement method emerging in recent years. It is the development of the traditional dynamic compaction method: specifically, the main difference between the dynamic compaction method and the high vacuum densification method lies in the fact that the former does not take effective way of drainage so that it is only applicable for the reinforcement of backfill with a low water content and its applicable scope is thus limited.

As for Hubei Xiantao Station located in Jianghan Plain and featured by high underground water level, abundant water volume and thick silt layer, to adopt the dynamic compaction method will probably make the soft soil become the "spring soil", which thus cannot meet the design requirement; however, the high vacuum densification method has taken the effective way of drainage, inserted the vacuum tube to increase the drainage channel, set up the improved drainage system so that it can effectively reduce the underground water level; moreover, coupled with the variable energy densification, it can be used for the reinforcement of the deep soft foundation; therefore, both of its reinforcement depth and applicable scope are much larger than those of the traditional dynamic compaction method.

Xiantao Station of Hankou-Yichang Railway was located at Hubei. The Freight Terminal of Xiantao Station adopted the reinforcement way combined with high vacuum densification plus plastic drainage board: the plastic drainage board was a way to reduce the underground pore water over a long period of time; however, under the condition with no external load imposed, its dewatering effect would not be obvious so that only with the external load imposed could it effectively reinforce the foundation. Xiantao Station was featured by soft foundation soil, poor structure, high underground water level, abundant water volume and thick silt layer, upon which with the method combined with vacuum dewatering and dynamic consolidation technology adopted, the goals of reinforcement both for the shallow and deep layers could be achieved at the same time.

Its reinforcement principle lay in the fact that the "differential pressure", actually, the excess pore water pressure generated by the densification was called as the "positive pressure" while the pressure generated by the operation of the vacuum pump was called as the "negative pressure", manually produced in the soil layer was to rapidly dissipate the excess pore water pressure and drain the water in the soft soil layer quickly. The adoption of the high vacuum drainage made the densification effect increased greatly, which thus made the processed soil mass formed into a consolidated "hard crust" with a certain thickness: the existence of the "hard crust" led to the effective extension of the surface load, which reduced the uneven settlement generated by the uneven load.

\section{Construction process}

After the construction scheme had been determined, it is time to confirm the construction process for the high vacuum densification; the specific construction process was shown as follows.

a Corresponding author: hsp0121@126.com 


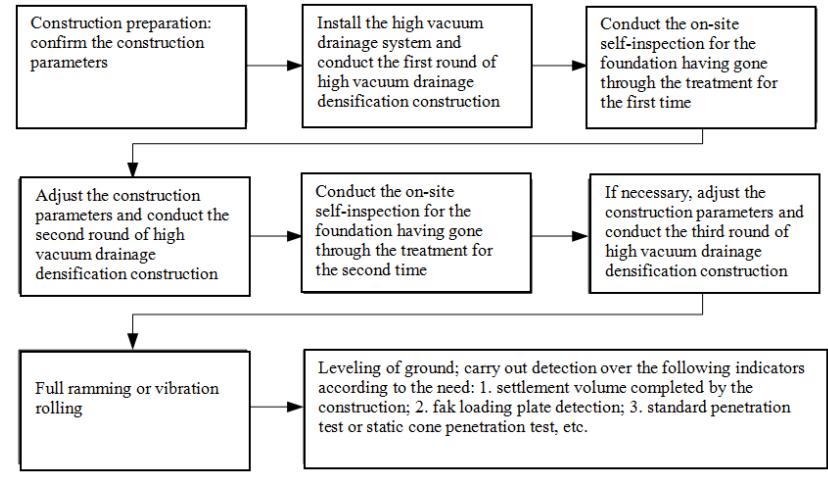

Figure 1. Construction process

\section{Densification Preparation}

\subsection{Field clearing}

Before the construction, the clearing, leveling and rolling were carried out first for the field to be treated so as to form a horizontal drainage slope larger than $1 \%$; and then the clean sand with a thickness of $0.5 \mathrm{~m}$ and the soil with a thickness of $1 \mathrm{~m}$ would be filled as the working layer for the high vacuum densification.

\subsection{Construction of the plastic drainage board}

After the ground had been leveled, the workers carried out the construction for the plastic drainage board; before the construction, workers filled the coarse sand with a thickness of $0.2 \mathrm{~m}$ as the underlying bed for the construction of the drainage board, upon which workers would implement the construction for the plastic drainage board. And then workers moved the machine into the construction site, put the drainage board into the drum and led the board into the pipeline through the pulley on the door frame; and then workers pulled out the drainage board from the pipeline, connected it with the pile tip, tightened it up, nestled it up to the pipeline shoe month and aimed it at the pile location. And then workers sank the pipeline into the design depth.

After the design depth had been reached, workers pulled out the pipeline. And then workers cut off the drainage board at the place $50 \mathrm{~cm}$ above the sand bed and buried it into the sand bed towards the flowing water slope direction. During the process of driving, it was necessary to carry out the self-inspection board by board and to make the construction records appropriately.

Meanwhile, it was necessary to check the construction condition for each piece of board and only when it met the acceptance criteria could the machine be moved to drive the next piece; during the pulling of the pipeline, it was necessary to prevent the drainage board from being drawn out: if the drawn-out length was larger than $0.5 \mathrm{~m}$, it was necessary to carry out the supplementary driving at the adjacent board. During the construction for the plastic plug board, workers had plugged the board "one by one" according to the "reverse driving" to ensure that the mark of the plug point would not be substantially damaged or moved.

Moreover, the variety, specification and quality of the plastic drainage board shall meet the design requirements. It would be better that if the plastic drainage board driven into the foundation was an entire board; the board shall not be lengthened for application. The coil belt of the plastic drainage board stacked at the construction site shall be properly covered so as to prevent it from being aged due to the exposure to the air; during the driving of the plastic drainage board, it was necessary to pay attention to the control over the perpendicularity of the pipeline, the deviation of which shall be not more than \pm $1 \%$; the steel pipeline shall not be bent and the permeable filter sleeve shall not be torn \& polluted so as not to affect the drainage effect.

The holes generated by the construction of the drainage board shall be backfilled with the medium-coarse sand in a timely manner so as to prevent the falling of the soil block. After the construction of the drainage board had been completed, it was necessary to pave a mediumcoarse sand bed with a thickness of $0.2 \mathrm{~m}$ on it for coverage.

\subsection{Determine the foundation coefficient}

Before the formal densification, what workers shall do first was to determine the foundation coefficient. Workers had adopted the static penetrometer to carry out the further investigation over the field to be treated; as for the area with larger geological differences, workers would divide it into different sub-areas and adopt different construction technology parameters.

Through the static cone penetration test, workers found that the geological conditions for the section DK83+420DK83+720 were basically the same; moreover, according to the mechanical equipment and labor force allocation, workers decided to divide the area into two construction sub-areas and to carry out the flow construction.

\subsection{Dredged the excavated ditch}

Workers deepened and dredged the excavated ditch between the freight yard and departure line to make it be the channel for vacuum drainage; meanwhile, workers dug the wells at the terminals of the ditch and drew the water by the pump to prevent the water accumulation in the ditch.

Moreover, workers dug the shockproof ditch between the mixing pile and the densification boundary to prevent the damage exerted by the densification on the pile body.

\subsection{Set up control piles}

Workers should set up control piles around the densification area; the control piles were 15 meters away from the densification boundary and one control pile was erected every 40 meters. Every densification construction 
sub-area would be equipped with one static cone penetration hole with a depth of $6-8 \mathrm{~m}$; before the treatment but after the dynamic compaction for each time, the test would be carried out. Two groups of hole pressure measuring points were set, the depth for both groups was $3 \mathrm{~m}, 5 \mathrm{~m}$ and $8 \mathrm{~m}$.

\subsection{Plug the vacuum pipeline}

After everything had been prepared, the key link was to plug the vacuum pipeline (according to the requirements of design, see the appended drawing); the vacuum construction adopted the $3 \mathrm{~m}$ pipeline to majorly adjust the water content of the soil $\&$ sand and the $6 \mathrm{~m}$ pipeline to majorly adjust the water content of the deep soil: specifically, the spacing between the vacuum pipelines was $3.5 \mathrm{~m} * 4.5 \mathrm{~m}$. The workers set up the peripheral high vacuum pipeline closed systems with spacing of $2 \mathrm{~m}$ outside the construction area, which was $2 \mathrm{~m}$ away from the construction boundary: specifically, the length of the deep sealing pipeline was $6-8 \mathrm{~m}$ while that of the shallow one was $3-4 \mathrm{~m}$. The peripheral high vacuum pipeline closed systems could not be demolished until the foundation treatment within the area had been finished.

The flow construction was carried out within this construction area; according to the actual condition of the peripheral sealing pipeline was not set separately so that the vacuum pipeline within the construction area would be used as the peripheral sealing pipeline.

During the pipeline plugging, the high-pressure water gun was used to punch the hole to assist the manual plugging; meanwhile, the mechanical pipeline plugging could also be adopted to improve the work efficiency. The vacuum pipeline adopted the $\Phi 32$ steel pipeline and the lower inlet opening was wrapped by two layers of nylon leakage membranes. The horizontal pipeline adopted the $\Phi 63$ PVC pipeline; the horizontal pipeline would be connected with the vacuum pipeline by the flexible rubber hose with the steel wire twined; meanwhile, the outside of the connection joint would be tightly sealed by the tape.

To prevent the damage of the filter screen, before the vacuum pipeline had been put into, it was necessary to check it carefully so as to ensure the intactness of the filter screen. After the completion of the pipeline plugging, it was necessary to connect the horizontal pipeline to the vacuum pump; each set of the unit shall be connected with $60-80$ vacuum pipelines at the same time to form a vacuum system. It is easy to know that the principle of the high vacuum densification is: the vacuum would lead to the pressure and thus achieve the effect to treat the soft foundation.

After the completion over the layout of the vacuum pipeline, workers were to carry out the vacuum drainage and start up the vacuum system: specifically, during the operation of the vacuum system, the vacuum degree could reach $60 \mathrm{KPa}$; during the construction period, the continuous water pumping would be conducted and the dual power supply would be prepared; specifically, the normal pumping rule would be "big then small, feculent then clear". 2-3 days before the pump starting, the pumping volume of each vacuum pump would be about 200 liters per hour while 4-7 days before the pump starting, the pumping volume of each vacuum pump would be about 50 liters per hour; during the construction process, through the measurement over the buried water level observation pipeline, when the water level dropped to the place 4 meters below the compaction surface, the densification construction shall be started.

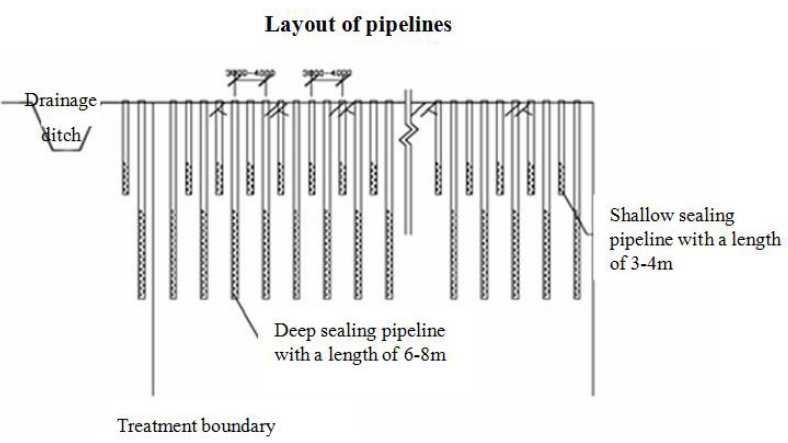

Figure 2. Plane schematic diagram for layout of vacuum pipelines

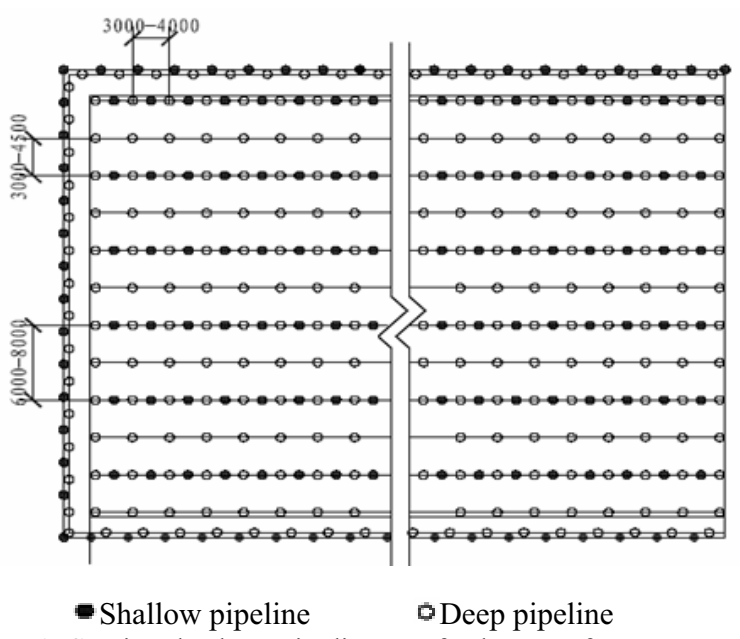

Figure 3. Sectional schematic diagram for layout of vacuum pipelines

\section{Densification Process}

After the above work had been prepared, workers can begin the first densification, which was distributed variable energy, according to the static cone penetration test and tracking tamping effect, and then adjusted densified energy according to the Ps-H curve. Before the formal densification construction, workers carried out single-point trial tamping within the field, to confirm the best tamping energy of the densification. Workers applied crawler crane of 50 tons for in-site densification, pounder with weight of 15 tons and diameter of 2.14 meters, with maximum lifting height of 14 meters. 
After the in-site trial tamping (based on the last two tamping sinkages less than $5 \mathrm{~cm}$ ), workers confirmed that: point tamping energy was $2000 \mathrm{KN}^{*} \mathrm{M} \quad(15$ tons $\left.* 10 \mathrm{KN}^{*} 13.3 \mathrm{~m}\right)$, and the full tamping energy was $800 \mathrm{KN}^{*} \mathrm{M}$. Effective reinforcement depth was: $\mathrm{H}=0.6 \mathrm{~V}$ $200=8.6$ meters $(0.6$ is geological factor, and takes 0.6 for sand layer; 200 is tamping energy, and its unit is tons meters.). The densification amount of each point was 4 and repeated 2 times, and full tamping was 1 time. The tamping points were distributed according to $3.5 \mathrm{~m}^{*} 6 \mathrm{~m}$, while two times tamping points were arranged in the form of quincunx.

After the completion of first densification, workers carried out a static cone penetration test and compared it with results before tamping, in order to adjust the parameters of next construction step; workers used bulldozers to level the tamping holes formation in the densification; workers arranged square grid by $20 \mathrm{~m} * 20 \mathrm{~m}$ to measure (level) settlement, and the measuring point location was consistent with that before tamping.

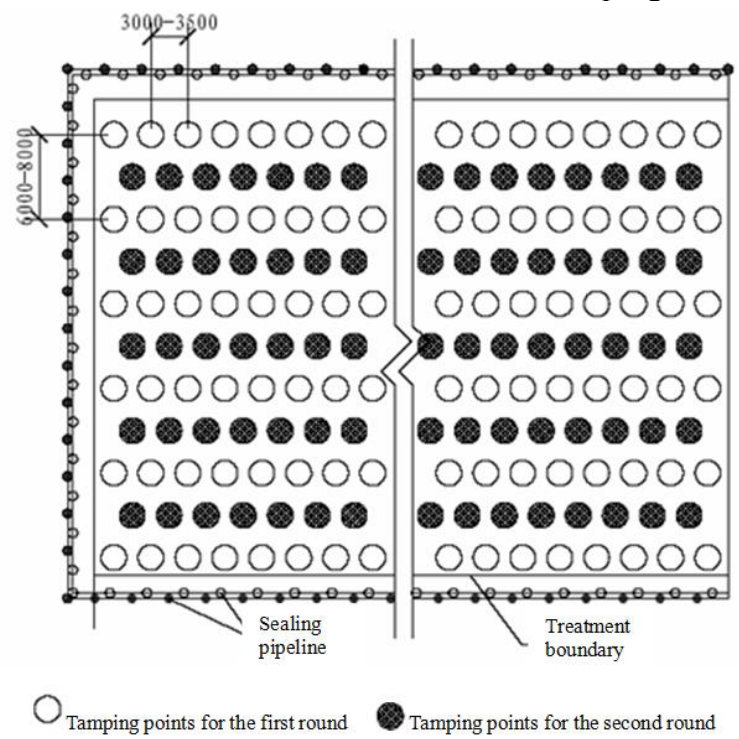

Figure 4. Tamping points during the densification process

After the completion of first densification, workers carried out a second high vacuum drainage, to continue adjusting the soil water content, in order to approach the best content for reinforced soil mass.

After the second high vacuum drainage, workers then began the second high vacuum densification. Through the embedded pore water pressure gauge, workers carried out the second one after the excess pore water pressure dissipated by $75 \%-85 \%$, with tamping points arranged by $3.5 \mathrm{~m} * 6 \mathrm{~m}$, in the form of quincunx similar to those of the first time. Point tamping energy was $2000 \mathrm{KN}^{*} \mathrm{M}$, the densification amount of each point was 4 , which was required to be same with the first densification.

Then workers had the third vacuum drainage which was the last one. After it, workers processed low energy full tamping; after excess pore water pressure dissipated by $75 \%-85 \%$, and after the completion of the above two high vacuum drainage densifications, the foundation below the densification hole bottom can be effectively reinforced, and the bearing capacity meet the expected design requirements; the soil above hole bottom was relatively loose, so workers carried out a low energy full tamping in order to further increase bearing capacity and stiffness of the upper foundation. The densification amount of each point was 1 .

So far, the whole construction process of high vacuum densification completed. The foundation after treatment reached its bearing capacity up to $125 \mathrm{Kpa}$.

\section{Conclusion}

Control points of high vacuum densification include: confirmation of densification parameter, confirm densification energy, densification drop distance, densification points through trial tamping. Control of densification construction process: static cone penetration test, underground water level observation, densification settlement measurement, vacuum degree observation of vacuum pump.

\section{References}

1. Pan Quan-Xiang. Data Handbook of Safety Production and Civilization Construction for Building Installation Works. Beijing: China Building Industry Press, 1995.

2. Hong Sheng-Wei. Practical Handbook for Quality Engineer. Beijing: China Metrology Press, 2004. 